\title{
Modified Medical Research Council scale vs Baseline Dyspnea Index to evaluate dyspnea in chronic obstructive pulmonary disease
}

This article was published in the following Dove Press journal:

International Journal of COPD

18 August 2015

Number of times this article has been viewed

\author{
Thierry Perez' \\ Pierre Régis Burgel ${ }^{2}$ \\ Jean-Louis Paillasseur ${ }^{3}$ \\ Denis Caillaud ${ }^{4}$ \\ Gaetan Deslée ${ }^{5}$ \\ Pascal Chanez ${ }^{6}$ \\ Nicolas Roche ${ }^{2}$ \\ For the INITIATIVES BPCO \\ Scientific Committee \\ 'Clinique des Maladies Respiratoires, \\ CHRU de Lille, Université Lille \\ Nord de France, Lille, ${ }^{2}$ Service de \\ Pneumologie, Groupe Hospitalier \\ Cochin Broca Hotel Dieu, AP HP et \\ Université René Descartes, ${ }^{3} \mathrm{EFFI}-$ \\ STAT, Paris, ${ }^{4}$ Service de Pneumologie, \\ Hôpital Gabriel Montpied, CHU de \\ Clermont Ferrand, Clermont Ferrand, \\ ${ }^{5}$ Service de Pneumologie, Hôpital \\ Maison Blanche, $\mathrm{CHU}$ de Reims, \\ Reims, ${ }^{6}$ Département des Maladies \\ respiratoires, AP-HM, Université de \\ Méditerranée, Marseille, France
}

Correspondence: Thierry Perez Clinique des Maladies Respiratoires, Hôpital Calmette, BD J Leclercq, 59037 Lille cedex,CHRU de Lille, Université de Lille, Lille, France

Email thierry.perez@chru-lille.fr
Background: Assessment of dyspnea in COPD patients relies in clinical practice on the modified Medical Research Council (mMRC) scale, whereas the Baseline Dyspnea Index (BDI) is mainly used in clinical trials. Little is known on the correspondence between the two methods. Methods: Cross-sectional analysis was carried out on data from the French COPD cohort Initiatives BPCO. Dyspnea was assessed by the mMRC scale and the BDI. Spirometry, plethysmography, Hospital Anxiety-Depression Scale, St George's Respiratory Questionnaire, exacerbation rates, and physician-diagnosed comorbidities were obtained. Correlations between mMRC and BDI scores were assessed using Spearman's correlation coefficient. An ordinal response model was used to examine the contribution of clinical data and lung function parameters to mMRC and BDI scores.

Results: Data are given as median (interquartile ranges, [IQR]). Two-hundred thirty-nine COPD subjects were analyzed (men 78\%, age 65.0 years [57.0; 73.0], forced expiratory volume in 1 second $\left[\mathrm{FEV}_{1}\right] 48 \%$ predicted $\left.[34 ; 67]\right)$. The $\mathrm{mMRC}$ grade and BDI score were, respectively, 1 [1-3] and 6 [4-8]. Both BDI and mMRC scores were significantly correlated at the group level (rho $=-0.67 ; P<0.0001$ ), but analysis of individual data revealed a large scatter of BDI scores for any given mMRC grade. In multivariate analysis, both mMRC grade and BDI score were independently associated with lower $\mathrm{FEV}_{1} \%$ pred, higher exacerbation rate, obesity, depression, heart failure, and hyperinflation, as assessed by the inspiratory capacity/total lung capacity ratio. The mMRC dyspnea grade was also associated with the thromboembolic history and low body mass index.

Conclusion: Dyspnea is a complex symptom with multiple determinants in COPD patients. Although related to similar factors (including hyperinflation, depression, and heart failure), BDI and mMRC scores likely explore differently the dyspnea intensity in COPD patients and are clearly not interchangeable.

Keywords: dyspnea, COPD, mMRC, BDI, quality of life, hyperinflation, depression, comorbidities

\section{Background}

COPD is a leading cause of mortality and morbidity worldwide. ${ }^{1}$ It is characterized by progressive airflow limitation; COPD severity was until recently mainly defined by the level of post-bronchodilator forced expiratory volume in 1 second $\left(\mathrm{FEV}_{1}\right){ }^{2}$ Dyspnea is the predominant symptom of COPD, both in stable condition and during exacerbations, and appears now as a major index of disease severity and a prominent target of treatment. Dyspnea has been shown to be weakly associated with the most common lung function parameters, particularly with $\mathrm{FEV}_{1}{ }^{3,4}$ suggesting the contribution of many other factors. Comorbidities, defined as specific chronic diseases distinct, 
and associated with COPD, are frequent in COPD and their importance is being increasingly recognized. ${ }^{5}$ They impact many aspects of the disease, and interfere with its natural history. For example, high rates of cardiovascular diseases (eg, chronic heart failure) and mood disorders (eg, anxiety and depression) have been reported in COPD patients ${ }^{5,6}$ and suggested as contributing to dyspnea. ${ }^{7,8}$

In daily practice, dyspnea level is usually measured by the modified Medical Research Council (mMRC) scale. This scale is easy to use and has a prognostic value, and was thus included in all simplified prognostic scores such as the Body mass index-airflow Obstruction-Dyspnea, and Exercise (BODE) index. ${ }^{9}$ Moreover, evaluation of the level of dyspnea by the $\mathrm{mMRC}$ is now used to categorize COPD symptomatic burden in the new Global initiative for chronic Obstructive Lung Disease (GOLD) recommendations and provides useful information about COPD-induced disability. ${ }^{2,10,11}$ However, its unidimensional structure and limited number of degrees are well-recognized limitations. Furthermore, a major disadvantage of mMRC is that it shows little change with therapeutic interventions. This led investigators to develop other tools for evaluating the impact of therapies on dyspnea levels. Among these tools, the Baseline Dyspnea Index (BDI) has been designed for a multidimensional assessment of dyspnea, and the corresponding Transition Dyspnea Index (TDI) appears to be much more sensitive to changes than the mMRC. ${ }^{3}$ The BDI/ TDI has been widely validated in COPD and remains the most frequently used questionnaire in clinical research, particularly for therapeutic trials. ${ }^{12-14}$ The correlations between mMRC and BDI scores for dyspnea assessment have been reported in two studies by Mahler et al ${ }^{12,15}$ with correlation coefficients between 0.61 and 0.73 . However, no details were given on individual concordance or discrepancies between these two measurements.

In the present study, the mMRC and BDI scores were used to evaluate dyspnea in COPD patients recruited in the INITIATIVES BPCO cohort. ${ }^{16}$ Our goals were 1) to analyze the relationships between $\mathrm{mMRC}$ scale and BDI score and 2) to evaluate the independent contributions of nutritional status, exacerbation rate, comorbidities (including anxietydepression), spirometry, and lung volumes to dyspnea levels, as assessed by mMRC vs BDI.

\section{Methods}

\section{The INITIATIVES BPCO cohort}

COPD subjects included in the present analysis were recruited in the INITIATIVES BPCO cohort between January
2005 and August 2009. The INITIATIVES BPCO cohort is a real-world cohort of clinically and spirometry-diagnosed COPD patients identified in 17 pulmonary units of university hospitals located throughout France. Data are recorded in a standardized case report form but, due to the real-world nature of patient care, datasets do not have to be complete to include a patient. Only demographic characteristics and spirometry are mandatory. Detailed information about this cohort can be found in a previous report. ${ }^{16}$ Respiratory physicians prospectively recruited subjects in stable condition (no history of exacerbation requiring medical treatment for the previous 4 weeks) with a diagnosis of COPD based on a post-bronchodilator $\mathrm{FEV}_{1} / \mathrm{FVC}$ (forced vital capacity) ratio $<70 \%$. ${ }^{17}$ Subjects with a main diagnosis of bronchiectasis, asthma, or any other significant respiratory diseases were carefully excluded. At the time of the analyses, the INITIATIVES BPCO cohort contained data on 633 COPD subjects. Because our goal was to study the impact of both lung function and comorbidities on dyspnea scores, we selected subjects with complete data for spirometry, plethysmography, comorbidities (coronary artery disease, chronic heart failure, thromboembolic history, diabetes, hypertension), Hospital Anxiety-Depression (HAD) Scale, Saint George's Respiratory Questionnaire (SGRQ) score to assess health-related quality of life (HRQoL), and numbers of acute exacerbations of COPD during the previous year. The study was approved by the Ethics Committee of Versailles (France), and all subjects provided informed written consent.

\section{Data collection}

We used a standardized characterization process that covered demographic data, risk factors including cumulative tobacco smoking, and COPD characteristics (including symptoms and spirometry) in stable condition. Pulmonary function tests were performed according to international standards, ${ }^{18}$ and included a spirometry and an optional plethysmographic assessment of lung volumes. Severity of airflow obstruction was evaluated according to GOLD classification. ${ }^{17}$ The number of acute exacerbations of COPD during the previous year was determined according to patient's selfreport. Comorbidities (including congestive heart failure, coronary artery disease, hypertension, and diabetes mellitus) were identified from the patient files (physician-diagnosed comorbidities). Malnutrition was defined by body mass index $(\mathrm{BMI}) \leq 18.5 \mathrm{~kg} / \mathrm{m}^{2}$ and obesity by a BMI $>30 \mathrm{~kg} / \mathrm{m}^{2}{ }^{19}$ Dyspnea was assessed by the $\mathrm{mMRC}$ scale ${ }^{11}$ ranging from 0 to 4 and by the French version of the BDI, previously validated in COPD. ${ }^{20}$ Total BDI score (0-12, 12 meaning no dyspnea) 
and individual dimensions (functional impairment, magnitude of task, and magnitude of effort, all three ranging from 0 to 4 ) were analyzed. The HAD scale was used to evaluate mood disorders. This 14-item self-questionnaire has two seven-item subscales for anxiety (HAD-A) and depression (HAD-D). Scores range from 0 to 21 for each subscale, and a score of 10 or higher on either subscale is closely associated with the presence of the corresponding mood disorder. ${ }^{21}$ HRQoL was evaluated using the original SGRQ. ${ }^{22}$

\section{Statistical analysis}

The normality of mMRC and BDI distribution was evaluated by a Shapiro-Wilk test $(W)$.

\section{Univariate analysis}

With qualitative variables, the values of $\mathrm{mMRC}$ and BDI are presented using median and IQR for each level of the variables, and Wilcoxon or Kruskal-Wallis tests were used.

With quantitative variables, the relations between mMRC and BDI scores are presented using Spearman correlation coefficients.

Variables of interest were age, symptoms of chronic bronchitis, $\mathrm{FEV}_{1}$, lung volumes, exacerbation frequency, HAD-anxiety and -depression subscores, nutritional status, and comorbidities including diagnosis of cardiovascular disease (chronic heart failure, coronary artery disease), venous thromboembolism, and diabetes.

\section{Multivariate analysis}

Stepwise ordinal logistic regressions were performed in order to find parameters that explain mMRC and BDI scores, using the LOGISTIC procedure from SAS ${ }^{\circledR} 9.2$ statistical software, with a significant level of entry of $15 \%$ and a significant level of stay of $10 \%$ as criteria for introducing or removing a covariate. For each score, two stepwise regressions were performed:

- Starting from no variable.

- Starting from all variables.

Each time, the two stepwise regressions converged to the same model.

Twelve variables were used as covariates.

Lung function variables were included as continuous ( $\mathrm{FEV}_{1} \%$ pred, $\mathrm{FVC} \%$ pred, functional residual capacity $[\mathrm{FRC}] \%$ pred) or categorical (inspiratory capacity/total lung capacity ratio [IC/TLC], $\geq 25 \%$ or $<25 \%$ ) variables. Comorbidities were included as individual variables. HAD-A and HAD-D were entered as no or significant anxiety/depression, corresponding to values $\geq 10$ for each subscore. BMI was entered as a categorical variable (low $<18.5 \mathrm{~kg} / \mathrm{m}^{2}$; obesity $>30 \mathrm{~kg} / \mathrm{m}^{2}$ ). Our univariate analysis showed a close relationship between dyspnea and HRQoL. We therefore deliberately excluded SGRQ from our multivariate analysis, to unmask other contributing factors.

\section{Results}

\section{Patients}

The present analysis included 239 subjects (53 women, 186 men) with a mean tobacco consumption of $42.6[25 ; 56]$ packyears. A comparison of the 239 patients with complete data to the remaining subjects with incomplete data was performed. Subjects with complete data had a tendency toward higher FVC (2.82 L vs $2.71 \mathrm{~L} ; P=0.08$ ), a higher rate of symptoms of chronic bronchitis ( $81 \%$ vs $67 \%, P=0.0003)$. No other differences were found between included and excluded subjects for clinical and lung function variables. All GOLD spirometry grades were represented (Table 1). Previously diagnosed comorbidities were found across all GOLD grades. The mean SGRQ total score was 45.3 [31.9; 60.9]. Mean $\mathrm{FEV}_{1}$ was $48 \%$ pred $[34 ; 67]$. Median $\mathrm{mMRC}$ and BDI scores were, respectively, $1[1 ; 3]$ and $6[4 ; 8]$. The distributions (Figure 1) of BDI and mMRC scores were non-Gaussian: for mMRC: $W=0.899, P<0.0001$; for BDI: $W=0.973, P=0.0002$. The mMRC grades and BDI scores correlated ( $\mathrm{rho}=-0.672$; $P<0.0001)$ at the group level, but large variations of BDI values were observed for a given mMRC grade (Figure 2). Although correlations were also found between mMRC and individual BDI dimensions (functional impairment: rho $=-0.621, P<0.0001 ;$ magnitude of task: rho $=-0.589$, $P<0.0001$; magnitude of effort: rho $=-0.581, P<0.0001)$, the dispersion of BDI subscores for each level of mMRC was as wide as for the total score (data not shown).

\section{Univariate determinants of $\mathrm{mMRC}$ and $\mathrm{BDI}$ scores}

Several categorical variables were related to $\mathrm{mMRC}$ and BDI scores, particularly a low BMI, depression, and severe hyperinflation (IC/TLC $<25 \%$ ) (Table 2 ). In addition, the $\mathrm{mMRC}$ and BDI scores were both highly correlated with SGRQ total score (Table 3). The correlation levels with lung function variables appeared similar for mMRC and BDI scores. BDI score and subscores were more closely correlated with clinical variables (SGRQ and HAD scores) than with lung function variables. Among them, the higher correlations were observed with $\mathrm{FEV}_{1}$, followed by the level of hyperinflation as assessed by IC/TLC and FRC/TLC. The relationships between mMRC and BDI scores with FRC\% pred and RV\% pred were significantly lower. 
Table I Description of patients characteristics by GOLD grade of airflow obstruction

\begin{tabular}{|c|c|c|c|c|}
\hline & GOLD I $(\mathbf{N}=\mid 5)$ & GOLD $2(\mathrm{~N}=98)$ & GOLD $3(\mathbf{N}=79)$ & GOLD $4(\mathrm{~N}=47)$ \\
\hline Age (years) & $74.0[47.0 ; 77.0]$ & $65.0[56.0 ; 72.0]$ & $64.0[57.0 ; 72.0]$ & $64.0[57.0 ; 73]$ \\
\hline BMI & $25.0[22.2 ; 29.7]$ & $25.5[23.3 ; 29.3]$ & $24.5[20.1 ; 28.3]$ & $22.4[18.8 ; 25.7]$ \\
\hline $\mathrm{FEV}_{1}$ (\% pred) & $85.2[83.7 ; 90.4]$ & $66.1[58.8 ; 72.7]$ & $40.9[35.0 ; 44.9]$ & $25.0[20.6 ; 29.3]$ \\
\hline FVC\% pred & 118 [109.7; 124.1$]$ & $95[87.4 ; 103.9]$ & $81.5[68.6 ; 92.7]$ & $75.9[62.9 ; 123.4]$ \\
\hline FRC\% pred & $128.6[100.8 ; 150.5]$ & I22.I [97.4; 139.9] & I53.7 [I25.7; I76.4] & $179.5[152.1 ; 2 \mid 2.7]$ \\
\hline RV\% pred & |48.8 [106.7; I79.8] & | 32.9 [104.6; 165.4] & I83.I [I54.6; 209.6] & $223.3[184.9 ; 261.7]$ \\
\hline IC/TLC & $0.37[0.35 ; 0.45]$ & $0.39[0.33 ; 0.45]$ & $0.28[0.22 ; 0.33]$ & $0.23[0.17 ; 0.26]$ \\
\hline HAD anxiety & $6.0[4.0 ; 10.0]$ & $7.0[4.0 ; 11.0]$ & $7.0[5.0 ; 10.0]$ & $8.0[4.0 ; 11.0]$ \\
\hline HAD depression & $6.0[2.0 ; 10.0]$ & $5.0[3.0 ; 8.0]$ & $6.0[3.0 ; 9.0]$ & $7.0[3.0 ; 10.0]$ \\
\hline BDI & $6[4 ; 10]$ & $7[6 ; 9]$ & $6[4 ; 7]$ & $4[3 ; 6]$ \\
\hline $\mathrm{mMRC}$ & I $[0 ; 3]$ & $\mathrm{I}[1 ; 2]$ & $2[1 ; 3]$ & $3[2 ; 3]$ \\
\hline \multicolumn{5}{|l|}{$\mathrm{mMRC}$} \\
\hline Grade 0 (\%) & $4(27 \%)$ & 24 (24\%) & $8(10 \%)$ & I (2\%) \\
\hline Grade I (\%) & $6(40 \%)$ & 48 (49\%) & $23(29 \%)$ & $6(13 \%)$ \\
\hline Grade 2 (\%) & I (7\%) & 15 (I5\%) & $24(30 \%)$ & $12(26 \%)$ \\
\hline Grade $3(\%)$ & $3(20 \%)$ & $7(7 \%)$ & 17 (22\%) & 18 (38\%) \\
\hline Grade 4 (\%) & I (7\%) & $4(4 \%)$ & $7(9 \%)$ & $10(21 \%)$ \\
\hline Heart failure (\%) & I (7\%) & $17(17 \%)$ & $12(15 \%)$ & $8(17 \%)$ \\
\hline Venous thromboembolic history (\%) & I (7\%) & $9(9 \%)$ & $6(8 \%)$ & $3(6 \%)$ \\
\hline \multicolumn{5}{|l|}{ BMI } \\
\hline$\leq 18.5 \mathrm{~kg} / \mathrm{m}^{2}$ & 0 & $\mathrm{I}(\mathrm{I} \%)$ & II (14\%) & $10(21 \%)$ \\
\hline$>30 \mathrm{~kg} / \mathrm{m}^{2}$ & $3(20 \%)$ & $21(21 \%)$ & $16(20 \%)$ & $5(11 \%)$ \\
\hline
\end{tabular}

Note: Data are shown as median [IQR] or $\mathrm{n}(\%)$.

Abbreviations: BDI, Baseline Dyspnea Index; BMI, body mass index; GOLD, Global initiative for chronic Obstructive Lung Disease; HAD, Hospital Anxiety-Depression; $\mathrm{FEV}_{\mathrm{I}}$, forced expiratory volume in I second; FRC, functional residual capacity; FVC, forced vital capacity; IC, inspiratory capacity; IQR, interquartile range; mMRC, modified Medical Research Council; RV, residual volume; TLC, total lung capacity.

For all variables but BMI, the Spearman correlation coefficients were higher with BDI functional impairment, lower with BDI magnitude of effort, and intermediate with BDI magnitude of task.

\section{Multivariate determinants of $\mathrm{mMRC}$ and $\mathrm{BDI}$ scores} Our univariate analysis showed a close relationship between dyspnea and HRQoL, according to previous studies. ${ }^{11,23} \mathrm{We}$, therefore, deliberately excluded SGRQ from our multivariate analysis, to unmask other contributing factors.

The results of ordinal logistic regression for $\mathrm{mMRC}$ grade and BDI score are shown in Tables 4 and 5; Figures 3 and 4.

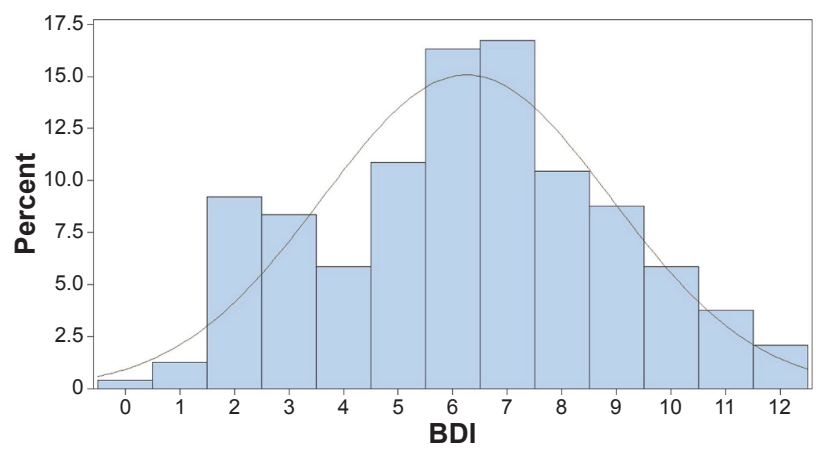

Figure I Distribution of the BDI score. Abbreviation: BDI, Baseline Dyspnea Index.
Major determinants (as indicated by high correlation coefficient values) were different for $\mathrm{mMRC}$ and BDI scores. For both scores, the first covariate was $\mathrm{FEV}_{1}$. Other independent determinants of both mMRC scale and BDI were exacerbation rate, obesity, heart failure, depression, and IC/TLC. Thromboembolic history and denutrition were significantly associated with the mMRC scale only.

Altogether, combining all independent determinants of dyspnea allowed us to explain only a moderate proportion of $\mathrm{mMRC}$ and $\mathrm{BDI}$ variations.

\section{Discussion}

In this cohort of COPD patients with a wide range of airflow limitation, mMRC dyspnea grades and BDI scores were correlated at the group level. However, for individual patients, large variations of BDI scores were observed for a given level of mMRC. The IQRs of BDI for each mMRC level were between 2 and 4 points, the larger being for mMRC 0 and 3. These two measurements shared most, but not all, of their determinants, which explained a moderate proportion of their variations. These data suggested that $\mathrm{mMRC}$ and BDI scores explore quite differently the dyspnea intensity in COPD patients and thus should ideally be used in combination. 
Total BDI

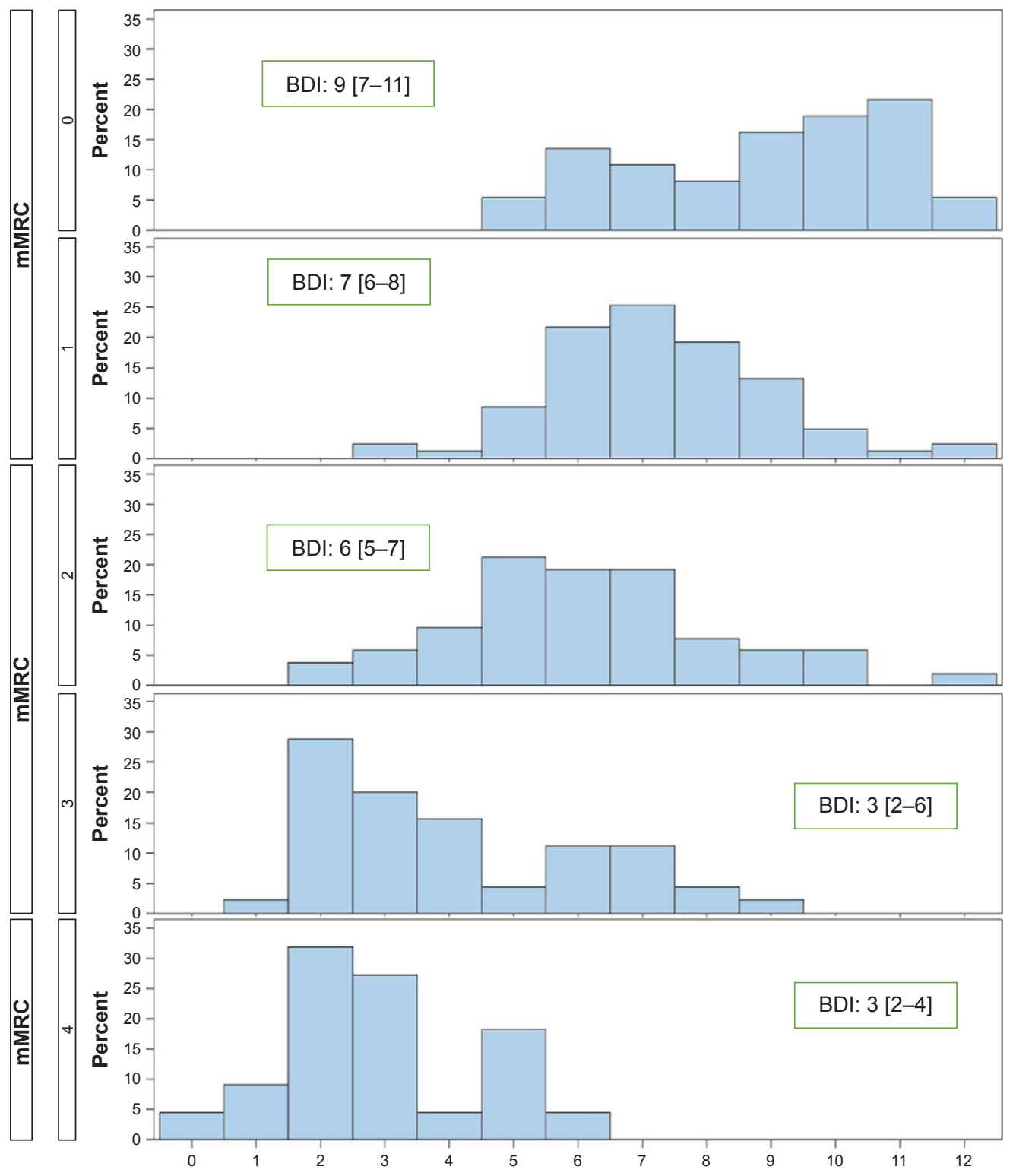

Figure 2 Relationships between BDI and mMRC scores in COPD patients. The median value and interquartile range of BDI are indicated for each mMRC level. Abbreviations: BDI, Baseline Dyspnea Index; COPD, chronic obstructive pulmonary disease; mMRC, modified Medical Research Council.

\section{mMRC scale vs BDI}

The use of appropriate measurement tools and the understanding of the determinants of dyspnea may help the clinician in the management of individual patients. The absence of a gold standard to assess dyspnea has to be underlined. Our results obtained in a large cohort of stable patients with well-defined COPD demonstrate that mMRC scale and BDI may refer to markedly different levels of dyspnea severity on an individual basis. In the two studies by Mahler et al enrolling 101 and 66 patients, the correlation coefficients between $\mathrm{mMRC}$ and BDI scores ranged from 0.61 to 0.73 , but no further details were provided about the magnitude of discrepancies between these tools. Another study comparing the mMRC, BDI, and oxygen cost diagram concluded that these tools were equivalent in a cross-sectional assessment, as they had the same distribution pattern. ${ }^{24}$ However, in all these studies, concordance at an individual level was not investigated or at least not reported. The BDI score has the potential advantage of covering several sensory components of dyspnea and might confer a more precise evaluation of dyspnea intensity and impact on daily life than mMRC. The sensitivity of BDI/TDI to longitudinal changes is also much higher. ${ }^{13,25}$ The reasons for marked dispersion of BDI scores for a given mMRC dyspnea level (particularly for mMRC grades 0 and 3 ) in our population are difficult to determine. 
Table 2 Univariate analysis of categorical variables associated with $\mathrm{mMRC/BDI}$

\begin{tabular}{|c|c|c|c|c|}
\hline \multirow[t]{2}{*}{ Variables } & \multirow[t]{2}{*}{ Index } & \multicolumn{2}{|c|}{ Median [IQR] } & \multirow{2}{*}{$\begin{array}{l}\text { Wilcoxon } \\
P \text {-value }\end{array}$} \\
\hline & & Men & Women & \\
\hline \multirow[t]{3}{*}{ Sex } & $\mathrm{BDI}$ & $6[5 ; 8]$ & $6[3 ; 8]$ & 0.238 \\
\hline & $\mathrm{mMRC}$ & $\mathrm{I}[1 ; 3]$ & $2[1 ; 3]$ & 0.036 \\
\hline & & Yes & No & \\
\hline \multirow[t]{2}{*}{ Chronic bronchitis } & $\mathrm{BDI}$ & $6[5 ; 8]$ & $6[4 ; 8]$ & 0.699 \\
\hline & $\mathrm{mMRC}$ & $2[1 ; 3]$ & I $[1 ; 3]$ & 0.567 \\
\hline Venous thromboembolic & $\mathrm{BDI}$ & $6[2 ; 7]$ & $6[4.5 ; 8]$ & 0.268 \\
\hline history & $\mathrm{mMRC}$ & $3[1 ; 3]$ & $I[1 ; 3]$ & 0.019 \\
\hline \multirow[t]{2}{*}{ Heart failure } & $\mathrm{BDI}$ & $5.5[3 ; 7]$ & $6[5 ; 8]$ & 0.087 \\
\hline & $\mathrm{mMRC}$ & $2[1 ; 3]$ & $\mathrm{I}[1 ; 3]$ & 0.024 \\
\hline \multirow[t]{2}{*}{ Low BMI $\leq 18.5 \mathrm{~kg} / \mathrm{m}^{2}$} & BDI & $4[3 ; 6]$ & $7[5 ; 8]$ & $<0.0001$ \\
\hline & $\mathrm{mMRC}$ & $2[1 ; 3]$ & $\mathrm{I}[1 ; 3]$ & 0.3431 \\
\hline \multirow{3}{*}{ Obesity } & BDI & $6[5 ; 8]$ & $6[4 ; 8]$ & 0.8822 \\
\hline & $\mathrm{mMRC}$ & $2[1 ; 3]$ & $\mathrm{I}[1 ; 3]$ & 0.5864 \\
\hline & & HAD $<10$ & $H A D \geq 10$ & \\
\hline \multirow[t]{2}{*}{ Anxiety } & $\mathrm{BDI}$ & $7[5 ; 8]$ & $5.5[3 ; 7]$ & 0.003 \\
\hline & $\mathrm{mMRC}$ & $\mathrm{I}[\mathrm{I} ; 2]$ & $2[1 ; 3]$ & 0.001 \\
\hline \multirow[t]{3}{*}{ Depression } & $\mathrm{BDI}$ & $7[5 ; 8]$ & $4[3 ; 6]$ & $<0.0001$ \\
\hline & $\mathrm{mMRC}$ & $\mathrm{I}[\mathrm{I} ; 2]$ & $3[1 ; 3]$ & 0.00014 \\
\hline & & $<\mathbf{2 5} \%$ & $\geq \mathbf{2 5} \%$ & \\
\hline \multirow[t]{2}{*}{ IC/TLC } & $\mathrm{BDI}$ & $5[3 ; 6]$ & $7[5 ; 8]$ & $<0.0001$ \\
\hline & $\mathrm{mMRC}$ & $3[2 ; 3]$ & I $[1 ; 2]$ & $<0.0001$ \\
\hline
\end{tabular}

Abbreviations: BDI, Baseline Dyspnea Index; BMI, body mass index; HAD, Hospital Anxiety-Depression; IC, inspiratory capacity; IQR, interquartile range; mMRC, modified Medical Research Council; TLC, total lung capacity.

Clinical and lung function correlates of dyspnea were very similar for both questionnaires, except for thromboembolic history and denutrition. However, the proportion of mMRC variance explained by these two variables was low and these comorbidities were found in only a minority of patients.
Clearly, our results demonstrate that $\mathrm{mMRC}$ and BDI scores are not interchangeable for the assessment of dyspnea in an individual patient. mMRC remains a standard tool to evaluate dyspnea in daily practice, and its usefulness is highly emphasized in the new GOLD document. Although the suggested cut-off to define significant symptoms was set at grade 2 , recent data suggest that patients with mMRC grade 1 may already exhibit a significant impact of COPD, as assessed by the COPD assessment test (CAT) score. ${ }^{26}$ However, the vast majority of our patients with grade 1 mMRC had a BDI $\geq 5$ (Figure 2). The reproducibility of mMRC and BDI scores in stable COPD patients have been found to be satisfactory, ${ }^{15,20}$ although it might be less for the "classic" BDI than with the self-administered version, ${ }^{12}$ which is not available in French at present. The discrepancies between BDI and MRC assessments are therefore likely to be reproducible, but the present study was not designed to answer this question.

\section{Determinants of dyspnea}

The second main finding of present study is that $\mathrm{FEV}_{1}$, hyperinflation, depression, and comorbidities are all major determinants of mMRC and BDI dyspnea scores. Determinants of dyspnea remain poorly understood in COPD due to the complexity of this symptom and its interindividual variability for the same level of physiologic impairment, for instance, $\mathrm{FEV}_{1}$. The moderate relationship with spirometry has been previously found using both mMRC and BDI scores, ${ }^{3}$

Table 3 Univariate analysis of $\mathrm{mMRC/BDI}$ correlates, using numerical variables

\begin{tabular}{|c|c|c|c|c|c|c|}
\hline & & \multicolumn{5}{|c|}{ Spearman correlation coefficients (rho) } \\
\hline & & mMRC & $\begin{array}{l}\text { BDI } \\
\text { total }\end{array}$ & $\begin{array}{l}\text { BDI functional } \\
\text { impairment }\end{array}$ & $\begin{array}{l}\text { BDI magnitude } \\
\text { of task }\end{array}$ & $\begin{array}{l}\text { BDI magnitude } \\
\text { of effort }\end{array}$ \\
\hline \multirow[t]{2}{*}{ Age } & rho & 0.10816 & -0.04967 & -0.02118 & -0.01477 & -0.11339 \\
\hline & $P$-value & 0.0953 & 0.4447 & 0.7446 & 0.8203 & 0.0802 \\
\hline \multirow[t]{2}{*}{$\mathrm{BMI}, \mathrm{kg} / \mathrm{m}^{2}$} & rho & -0.04476 & 0.19451 & 0.16882 & 0.21523 & 0.12184 \\
\hline & $P$-value & 0.4910 & 0.0025 & 0.0089 & 0.0008 & 0.0600 \\
\hline \multirow[t]{2}{*}{ SGRQ } & rho & 0.66602 & -0.69067 & -0.65152 & -0.59262 & -0.57354 \\
\hline & $P$-value & $<0.0001$ & $<0.0001$ & $<0.0001$ & $<0.0001$ & $<0.000$ I \\
\hline \multirow[t]{2}{*}{ HAD anxiety } & rho & 0.19222 & -0.21341 & -0.24333 & $-0.1707 \mid$ & -0.09802 \\
\hline & $P$-value & 0.0028 & 0.0009 & 0.0001 & 0.0082 & 0.1308 \\
\hline \multirow[t]{2}{*}{ HAD depression } & rho & 0.30348 & -0.40110 & -0.41325 & -0.36808 & -0.25213 \\
\hline & $P$-value & $<0.0001$ & $<0.0001$ & $<0.0001$ & $<0.0001$ & $<0.000 \mathrm{I}$ \\
\hline \multirow[t]{2}{*}{$\mathrm{FEV}_{1} \%$ pred } & rho & -0.45100 & $0.407 / 3$ & 0.39529 & 0.34706 & 0.27785 \\
\hline & $P$-value & $<0.0001$ & $<0.0001$ & $<0.0001$ & $<0.0001$ & $<0.0001$ \\
\hline \multirow[t]{2}{*}{ FVC\% pred } & rho & -0.26632 & 0.22602 & 0.22084 & 0.20309 & 0.13053 \\
\hline & $P$-value & $<0.0001$ & 0.0004 & 0.0006 & 0.0016 & 0.0438 \\
\hline \multirow[t]{2}{*}{ IC/TLC\% } & rho & -0.37503 & 0.33243 & 0.32347 & 0.27679 & 0.20506 \\
\hline & $P$-value & $<0.0001$ & $<0.0001$ & $<0.000$ I & $<0.000$ I & 0.0014 \\
\hline
\end{tabular}

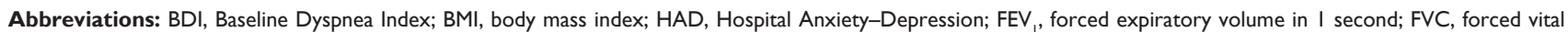
capacity; IC, inspiratory capacity; TLC, total lung capacity; mMRC, modified Medical Research Council. 
Table 4 Determinants of the $\mathrm{mMRC}$ scale in stepwise multivariate analysis

\begin{tabular}{|c|c|c|c|c|c|c|}
\hline \multicolumn{7}{|c|}{ Analysis of maximum likelihood estimates } \\
\hline Parameter & Unit & DF & Estimate & Standard error & Wald $\chi^{2}$ & $\operatorname{Pr}>\chi^{2}$ \\
\hline $\mathrm{BMI} \leq 18.5 \mathrm{~kg} / \mathrm{m}^{2}$ & Yes & 1 & 0.8422 & 0.4419 & 3.6326 & 0.0567 \\
\hline Obesity & Yes & I & -0.6220 & 0.3150 & 3.8985 & 0.0483 \\
\hline $\mathrm{FEV}_{1}$ & \%pred & 1 & 0.0391 & 0.00785 & 24.7789 & $<0.0001$ \\
\hline IC/TLC class & $<25 \%$ & 1 & 0.6994 & 0.3237 & 4.6689 & 0.0307 \\
\hline HAD depression & $\geq 10$ & 1 & -0.8960 & 0.3008 & 8.8746 & 0.0029 \\
\hline Exacerbations rate & $\mathrm{n} /$ year & I & -0.1621 & 0.0547 & 8.7854 & 0.0030 \\
\hline Heart failure & Yes & 1 & -0.8884 & 0.3289 & 7.2974 & 0.0069 \\
\hline Venous thromboembolic history & Yes & I & $-|.054|$ & 0.4461 & 5.5819 & 0.0181 \\
\hline
\end{tabular}

Abbreviations: BMI, body mass index; DF, degree of freedom; HAD, Hospital Anxiety-Depression; FEV , forced expiratory volume in I second; IC, inspiratory capacity; mMRC, modified Medical Research Council; TLC, total lung capacity.

although overall dyspnea scores deteriorate significantly with GOLD stages. ${ }^{15}$ Our results confirm these data. ${ }^{27,28}$

In our patients, hyperinflation was a significant determinant of dyspnea, but the correlation was lower than for $\mathrm{FEV}_{1}$. A few studies have evaluated the relationship between dyspnea and the level of resting hyperinflation. Nishimura et al recently showed a significant relationship with dyspnea, but these authors also found a lower level of correlation than for $\mathrm{FEV}_{1}{ }^{29} \mathrm{~A}$ similar level of correlation with dyspnea intensity was found for RV/TLC. ${ }^{24}$ Our results with IC/TLC confirm these findings.

Although dyspnea is classically more severe in COPD patients with significant anxiety, ${ }^{6,30}$ conflicting results have been reported recently ${ }^{31}$ Notably, factor analysis demonstrated that anxiety was found to be a clearly different factor from dyspnea. ${ }^{24}$ Although significant in univariate analysis, anxiety was no longer a contributing factor in our multivariate analysis, especially after taking into account the level of depression.

Depression is a frequent comorbidity of COPD, although its prevalence varies widely among studies. ${ }^{8}$ The relationship between depression and dyspnea has, however, been less investigated than for anxiety. Sanchez et al recently performed a principal component analysis including dyspnea (MRC and BDI), HRQoL, HAD score, and plethysmography data in a large population of 328 patients with altered ventilatory capacity, including 128 COPD patients. Surprisingly, psychological status and dyspnea appeared as separate dimensions. ${ }^{28}$ The authors hypothesized that BDI and MRC only reflected the sensory dimension of dyspnea, thus neglecting its affective component. Conversely, another study also found that depression was a significant contributor to low HRQoL (SGRQ) in multivariate analysis..$^{23}$ In our patients, depression appeared much more significantly associated with dyspnea assessed by BDI in multivariate analysis than by mMRC. Treatment of depression in COPD may improve symptoms and HRQoL in COPD patients, ${ }^{32}$ but randomized studies are clearly lacking to evaluate its impact on dyspnea.

Exacerbation rate is significantly associated with dyspnea in both $\mathrm{mMRC}$ and BDI models. The relation between exacerbations and dyspnea is well demonstrated as well as their negative impact on HRQoL. ${ }^{23}$ Our patients were evaluated in stable condition, but repeated exacerbations may play a role in anticipating forthcoming episodes of increased dyspnea and limitation, leading to what can be called "kinesiophobia" or dyspnea-related fear. ${ }^{31}$

The relationship with thromboembolic history was rather unexpected since 1) no suspicion of post-embolic pulmonary hypertension was found and 2) the prevalence of chronic

Table 5 Determinants of the BDI total score in stepwise multivariate analysis

\begin{tabular}{|c|c|c|c|c|c|c|}
\hline \multicolumn{7}{|c|}{ Analysis of maximum likelihood estimates } \\
\hline \multicolumn{7}{|c|}{$\begin{array}{l}\text { Analysıs of maxımum Ilkellinood estımates } \\
\text { Parameter } \quad \text { Unit }\end{array}$} \\
\hline Obesity & Yes & I & 0.5180 & 0.3077 & 2.8352 & 0.0922 \\
\hline $\mathrm{FEV}_{1}$ & $\%$ pred & I & -0.0252 & 0.00734 & $1 \mathrm{I} .7574$ & 0.0006 \\
\hline IC/TLC class & $<25 \%$ & I & -0.5617 & 0.3177 & 3.1256 & 0.0771 \\
\hline HAD depression & $\geq 10$ & I & 1.2797 & 0.2997 & 18.2346 & $<0.0001$ \\
\hline Exacerbation rate & $\mathrm{n} /$ year & I & 0.1515 & 0.0537 & 7.9483 & 0.0048 \\
\hline Heart failure & Yes & 1 & 0.7912 & 0.3243 & 5.9522 & 0.0147 \\
\hline
\end{tabular}

Abbreviations: BDI, Baseline Dyspnea Index; DF, degree of freedom; HAD, Hospital Anxiety-Depression; FEV , forced expiratory volume in I second; IC, inspiratory capacity; TLC, total lung capacity. 


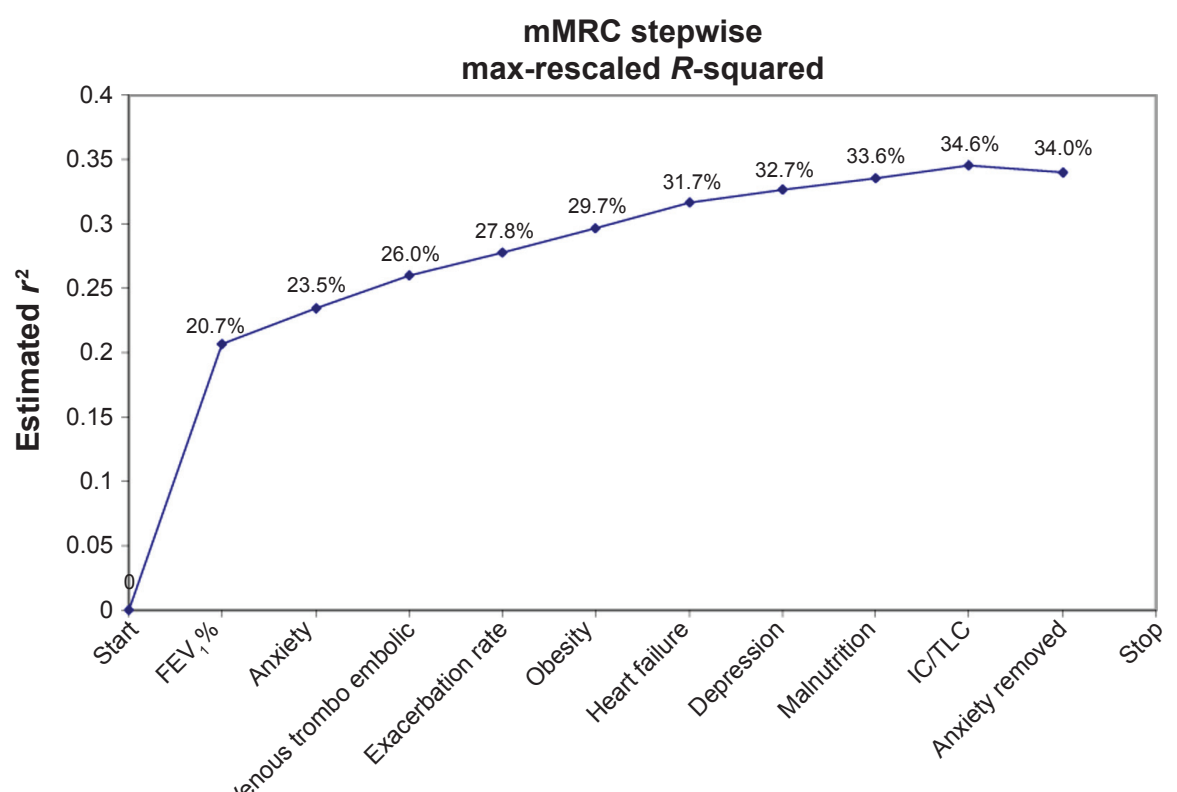

Added variable

Figure 3 Determinants of the mMRC grade (stepwise logistic regression).

Abbreviations: BDI, Baseline Dyspnea Index; FEV , forced expiratory volume in I second; IC, inspiratory capacity; mMRC, modified Medical Research Council; TLC, total lung capacity.

post-embolic pulmonary hypertension after a first episode was low. ${ }^{33}$ However, it must be acknowledged that patients were not systematically assessed for chronic thromboembolic pulmonary hypertension.

Heart failure is a frequent comorbidity in COPD patients and plays a role in dyspnea, although it seems difficult to determine its precise contribution in individual patients. Dyspnea is more severe in patients with systolic heart failure and coexisting COPD, and increases with GOLD stages. ${ }^{26}$ We cannot exclude an underdiagnosis of heart

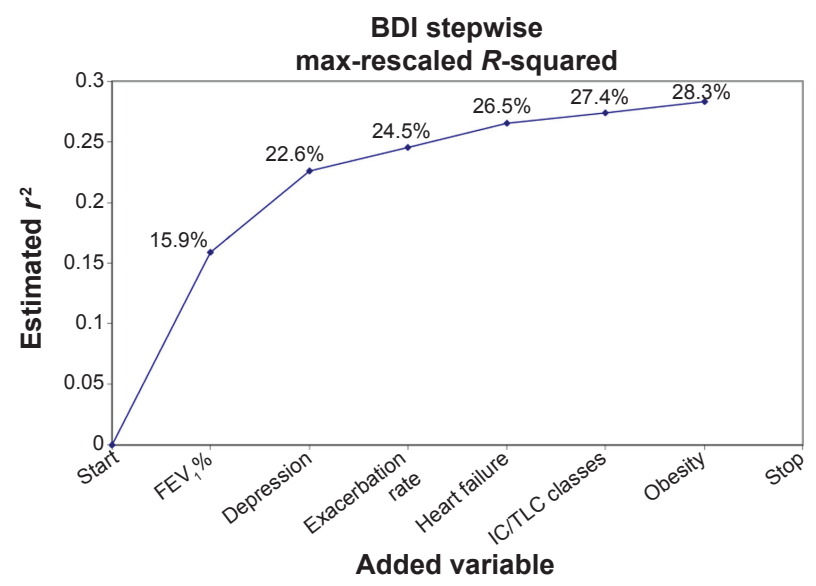

Figure 4 Determinants of the BDI score (stepwise logistic regression). Abbreviations: BDI, Baseline Dyspnea Index; $\mathrm{FEV}_{1}$, forced expiratory volume in I second; IC, inspiratory capacity; TLC, total lung capacity. failure (particularly diastolic) in some patients because of the absence of systematic investigations.

Obesity was a contributing factor in both BDI and mMRC models. Conversely, it was recently suggested that moderate obesity could improve dyspnea during exercise in COPD, through its limiting effect on hyperinflation during exercise, but this hypothesis remains controversial. ${ }^{34}$

Higher degrees of dyspnea are often reported in female COPD patients for a comparable level of $\mathrm{FEV}_{1}$ impairment. Such a finding was recently confirmed in our cohor ${ }^{35}$ after a careful matching for age and $\mathrm{FEV}_{1}$ level of male vs female patients (3:1 ratio). The difference for mMRC grade was similar in our subset of patients in univariate analysis (mMRC grade 1 in males vs grade 2 in females) but disappeared in the multiple regression. This difference is probably related to the multivariate analysis per se as well as to sampling differences in our cohort between the two studies.

One important strength of the present study is the systematic, simultaneous assessment of comprehensive lung function variables (including lung volumes) and clinical variables. In addition to the simple mMRC scale, we used the BDI score, which remains at present the most sensitive questionnaire to assess the severity of dyspnea and dyspnearelated impact on exercise and activity.

The present study also has some limitations. Our patients were recruited in pulmonary clinics of university 
hospitals, and therefore may not represent the COPD population at large, with a lower proportion of stage I patients. However, they had a wide range of airflow limitation, indicating various degrees of spirometric severity. The emotional aspects of dyspnea were not assessed due to the MRC and BDI measuring properties. New questionnaires include this dimension and may provide additional information about dyspnea components. ${ }^{36,37}$ The relationships of these new questionnaires with other COPD components or outcomes remain to be confirmed in large field studies. Another limitation of the present study is that the severity of comorbidities (eg, heart failure) was not precisely assessed. Other potential contributing lung function parameters were unavailable, particularly $\mathrm{DL}_{\mathrm{CO}}$, inspiratory muscle strength, expiratory flow limitation, and airway resistance. The latter, either assessed by plethysmography or forced oscillation, was recently shown to correlate significantly with dyspnea in COPD patients. ${ }^{38}$ Exercise capacity and physical activity were also not evaluated in our study.

However, dyspnea is likely to be a determinant of exercise tolerance and not the contrary, although regular physical activity may play a positive role through its impact on deconditioning.

\section{Conclusion}

In conclusion, this study shows that, although related on a statistical ground, mMRC and BDI scores may evaluate very differently the dyspnea intensity in individual patients. BDI and mMRC scale thus appear complementary, in the absence of a gold standard tool. New self-administered questionnaires are clearly needed, evaluating both sensory and affective components of dyspnea. These questionnaires should also be highly sensitive to changes, particularly therapeutic interventions. Present results also confirm the complexity of dyspnea determinants in COPD and suggest a significant impact of frequent exacerbations, hyperinflation, and common comorbidities, particularly heart failure and depression.

\section{Acknowledgments}

The Initiatives BPCO study group consisted of G BrinchaultRabin (Rennes), P-R Burgel (Paris), D Caillaud (ClermontFerrand), P Carré (Carcassonne), P Chanez (Marseille), A Chaouat (Vandœuvre les Nancy), I Court-Fortune (SaintEtienne), A Cuvelier (Rouen), R Escamilla (Toulouse), C Gut-Gobert (Brest), G Jebrak (Paris), F Lemoigne (Nice), P Nesme-Meyer (Lyon), T Perez and the late I Tillie-Leblond
(Lille), C Perrin (Cannes), C Pinet (Toulon), C Raherison (Bordeaux), and N Roche (Paris). This work was funded by unrestricted grants from Boehringer Ingelheim France and Pfizer France.

\section{Author contributions}

TP, PRB, and NR contributed to study design, statistical analysis plan, and preparation of manuscript; JLP performed the statistical analysis; DC, GD, and PC contributed to manuscript revision. All authors contributed toward database design, patient recruitment, data analysis, drafting and critically revising the paper and agree to be accountable for all aspects of the work.

\section{Disclosure}

The authors report no conflicts of interest in this work.

\section{References}

1. Halbert RJ, Natoli JL, Gano A, Badamgarav E, Buist AS, Mannino DM. Global burden of COPD: systematic review and global analysis. Eur Respir J. 2006;28(3):523-532.

2. GOLD. Global Strategy for the Diagnosis, Management and Prevention of COPD, Global Initiative for Chronic Obstructive Lung Disease (GOLD). 2010. Available from: http://www.goldcopd.org/guidelines-globalstrategy-for-diagnosis-management.html . Accessed April 25th, 2015.

3. Mahler DA, Weinberg DH, Wells CK, Feinstein AR. The measurement of dyspnea. Contents, interobserver agreement, and physiologic correlates of two new clinical indexes. Chest. 1984;85(6): 751-758.

4. Ferrari K, Goti P, Misuri G, et al. Chronic exertional dyspnea and respiratory muscle function in patients with chronic obstructive pulmonary disease. Lung. 1997;175(5):311-319.

5. Fabbri LM, Luppi F, Beghe B, Rabe KF. Complex chronic comorbidities of COPD. Eur Respir J. 2008;31:204-212.

6. Maurer J, Rebbapragada V, Borson S, et al; ACCP Workshop Panel on Anxiety and Depression in COPD. Anxiety and depression in COPD current understanding, unanswered questions, and research needs. Chest. 2008;134(4 suppl):43S-56S.

7. Le Jemtel TH, Padeletti M, Jelic S. Diagnostic and therapeutic challenges in patients with coexistent chronic obstructive pulmonary disease and chronic heart failure. J Am Coll Cardiol. 2007;49(2): 171-180.

8. von Leupoldt A, Taube K, Lehmann K, Fritzsche A, Magnussen H. The impact of anxiety and depression on outcomes of pulmonary rehabilitation in patients with COPD. Chest. 2011;140(3):730-736.

9. Celli BR, Cote CG, Marin JM, et al. The body-mass index, airflow obstruction, dyspnea, and exercise capacity index in chronic obstructive pulmonary disease. N Engl J Med. 2004;350(10):1005-1012.

10. Vestbo J, Hurd SS, Agusti AG, et al. Global strategy for the diagnosis, management, and prevention of chronic obstructive pulmonary disease: GOLD executive summary. Am J Respir Crit Care Med. 2013; 187(4):347-365.

11. Bestall JC, Paul EA, Garrod R, Garnham R, Jones PW, Wedzicha JA. Usefulness of the Medical Research Council (MRC) dyspnoea scale as a measure of disability in patients with chronic obstructive pulmonary disease. Thorax. 1999;54(7):581-586.

12. Mahler DA, Waterman LA, Ward J, McCusker C, ZuWallack R, Baird JC. Validity and responsiveness of the self-administered computerized versions of the baseline and transition dyspnea indexes. Chest. 2007;132(4):1283-1290. 
13. Jones P, Miravitlles M, van der Molen T, Kulich K. Beyond FEV(1) in COPD: a review of patient-reported outcomes and their measurement. Int J Chron Obstruct Pulmon Dis. 2012;7:697-709.

14. Donohue JF, Fogarty C, Lötvall J, et al; INHANCE Study Investigators. Once-daily bronchodilators for chronic obstructive pulmonary disease: indacaterol versus tiotropium. Am J Respir Crit Care Med. 2010;182(2): $155-162$.

15. Mahler DA, Ward J, Waterman LA, McCusker C, Zuwallack R, Baird JC. Patient-reported dyspnea in COPD reliability and association with stage of disease. Chest. 2009;136(6):1473-1479.

16. Burgel PR, Nesme-Meyer P, Chanez P, et al; Initiatives Bronchopneumopathie Chronique Obstructive Scientific Committee. Cough and sputum production are associated with frequent exacerbations and hospitalizations in COPD subjects. Chest. 2009;135(4):975-982.

17. Rabe KF, Hurd S, Anzueto A, et al; Global Initiative for Chronic Obstructive Lung Disease. Global strategy for the diagnosis, management, and prevention of chronic obstructive pulmonary disease: GOLD executive summary. Am J Respir Crit Care Med. 2007;176:532-555.

18. Miller MR, Hankinson J, Brusasco V, et al; ATS/ERS Task Force. Standardisation of spirometry. Eur Respir J. 2005;26(2):319-338.

19. World Health Organization. Obesity: preventing and managing the global epidemic. Report of a WHO consultation. World Health Organ Tech Rep Ser. 2000;894:5-15.

20. Laurendeau C, Pribil C, Perez T, Roche N, Simeoni MC, Detournay B. [Validation study of the BDI/TDI scores in chronic obstructive pulmonary disease]. Rev Mal Respir. 2009;26(7):735-743.

21. Ng TP, Niti M, Tan WC, Cao Z, Ong KC, Eng P. Depressive symptoms and chronic obstructive pulmonary disease: effect on mortality, hospital readmission, symptom burden, functional status, and quality of life. Arch Intern Med. 2007;167:60-67.

22. Jones PW, Quirk FH, Baveystock CM, Littlejohns P. A self-complete measure for chronic airflow limitation: the St George's respiratory questionnaire. Am Rev Respir Dis. 1992;145(6):1321-1327.

23. Burgel P, Escamilla R, Perez T, et al. Impact of comordities on COPDspecific health-related quality of life. Respir Med. 2013;107:233-241.

24. Hajiro T, Nishimura K, Tsukino M, Ikeda A, Koyama H, Izumi T. Analysis of clinical methods used to evaluate dyspnea in patients with chronic obstructive pulmonary disease. Am J Respir Crit Care Med. 1998; 158(4):1185-1189.

25. Mahler DA, Ward J, Waterman LA, Baird JCD. Longitudinal changes in patient-reported dyspnea in patients with COPD. COPD. 2012;9:522-527.

26. Arnaudis B, Lairez O, Escamilla R, et al. Impact of chronic obstructive pulmonary disease severity on symptoms and prognosis in patients with systolic heart failure. Clin Res Cardiol. 2012;101(9):717-726.
27. Mahler DA, Rosiello RA, Harver A, Lentine T, McGovern JF, Daubenspeck JA. Comparison of clinical dyspnea ratings and psychophysical measurements of respiratory sensation in obstructive airway disease. Am Rev Respir Dis. 1987;135(6):1229-1233.

28. Sanchez O, Caumont-Prim A, Gillet-Juvin K, et al. Activity-related dyspnea is not modified by psychological status in people with COPD, interstitial lung disease or obesity. Respir Physiol Neurobiol. 2012;182(1):18-25.

29. Nishimura K, Yasui M, Nishimura T, Oga T. Airflow limitation or static hyperinflation: which is more closely related to dyspnea with activities of daily living in patients with COPD? Respir Res. 2011;12:135.

30. Giardino ND, Curtis JL, Andrei AC, et al; NETT Research Group. Anxiety is associated with diminished exercise performance and quality of life in severe emphysema: a cross-sectional study. Respir Res. 2010; 11:29.

31. Janssens T, De Peuter S, Stans L, et al. Dyspnea perception in COPD: association between anxiety, dyspnea-related fear, and dyspnea in a pulmonary rehabilitation program. Chest. 2011;140(3):618-625.

32. Eiser N, Harte R, Spiros K, Phillips C, Isaac MT. Effect of treating depression on quality-of-life and exercise tolerance in severe COPD. COPD. 2005;2(2):233-241.

33. Becattini C, Agnelli G, Pesavento R, et al. Incidence of chronic thromboembolic pulmonary hypertension after a first episode of pulmonary embolism. Chest. 2006;130(1):172-175.

34. Ora J, Laveneziana P, Wadell K, Preston M, Webb KA, O'Donnell DE. Effect of obesity on respiratory mechanics during rest and exercise in COPD. J Appl Physiol. 2011;111(1):10-19.

35. Roche N, Deslée G, Caillaud D, et al; INITIATIVES BPCO Scientific Committee. Impact of gender on COPD expression in a real-life cohort. Respir Res. 2014;15:20

36. Yorke J, Moosavi SH, Shuldham C, Jones PW. Quantification of dyspnoea using descriptors: development and initial testing of the dyspnoea-12. Thorax. 2010;65(1):21-26.

37. Meek PM, Banzett R, Parshall MB, Gracely RH, Schwartzstein RM, Lansing R. Reliability and validity of the multidimensional dyspnea profile. Chest. 2012;141(6):1546-1553.

38. Mahut B, Caumont-Prim A, Plantier L, et al. Relationships between respiratory and airway resistances and activity-related dyspnea in patients with chronic obstructive pulmonary disease. Int $J$ Chron Obstruct Pulmon Dis. 2012;7:165-171.
International Journal of COPD

\section{Publish your work in this journal}

The International Journal of COPD is an international, peer-reviewed journal of therapeutics and pharmacology focusing on concise rapid reporting of clinical studies and reviews in COPD. Special focus is given to the pathophysiological processes underlying the disease, intervention programs, patient focused education, and self management protocols.
Dovepress

This journal is indexed on PubMed Central, MedLine and CAS. The manuscript management system is completely online and includes a very quick and fair peer-review system, which is all easy to use. Visit http://www.dovepress.com/testimonials.php to read real quotes from published authors. 